\title{
O EXERCÍCIO PROFISSIONAL DE CIÊNCIAS AGRÁRIAS
}

\author{
The Professional Exercise of the Agrarian Science
}

\author{
Carlos Augusto Parchen \\ Eng. Agrônomo, M. Sc., Professor da PUCPR, Centro de Ciências Agrárias e Ambientais, \\ São José dos Pinhais - PR. E-mail: parchen@pr.gov.br.
}

\section{INTRODUÇÃO}

A necessidade da atuação dos profissionais de Ciências Agrárias nasce com os primórdios da agricultura, quando as atividades de produção dos alimentos foram baseadas nos recursos naturais disponíveis para cada coletividade. Com o contínuo crescimento da população, aumentava a necessidade de produção de alimentos, o que era conseguido pelo contínuo aumento das áreas cultivadas. No entanto, durante séculos, o produtor rural, com seu trabalho, acumulou conhecimentos do como produzir alimentos, que se constituíram num saber agrícola, repassado a cada geração. Embora esse sistema fizesse com que muitas das fundamentações teóricas sobre as práticas agrícolas utilizadas fossem equivocadas, ocorria o aperfeiçoamento do processo produtivo, sendo vários dos aspectos desse conhecimento validados e reproduzidos ainda nos dias atuais, tais como a escolha dos melhores solos, o pousio, a utilização de leguminosas, as rotações, as reciclagens, os sistemas integrados de produção animal e vegetal (CAVALLET, 1999).

O modelo de produção baseado no processo histórico, no entanto, mostrou-se incapaz de suprir as crescentes demandas, o que, aliado ao mercantilismo, iniciado no século XVI, possibilitou que a agricultura passasse de uma atividade meramente de sustentação da sociedade para transformarse em atividade comercial com busca de lucro. Em decorrência, com o avanço dos conhecimentos em diferentes áreas e a estruturação crescente do capitalismo, foi possível o surgimento, no início do século XIX, da Agronomia como um ramo das ciências naturais que buscava estudar cientificamente o desenvolvimento da agricultura. Caberia à Agronomia a atribuição de pensar, com base em um saber científico, na agricultura e suas relações. Com isso, o domínio do saber agrícola, até então acumulado no homem do campo, foi se deslocando para os meios intelectuais e incorporado na tecnologia, restando ao produtor rural meramente a execução das atividades de produção (CAVALLET, 1999).

Desde seu surgimento no Brasil, como ciência, a Agronomia, em cerca de dois séculos, contribuiu de maneira decisiva na alteração das formas de produção na agricultura. No enfoque do seu objetivo principal, dentro dos pressupostos que estruturaram a sua criação e organização como ciência, que era a viabilização da produção agrícola em quantidades e preços adequados ao comércio capitalista, atingiu amplamente seus objetivos (CAVALLET, 1999). 


\section{Um rápido histórico}

Conforme Florençano e Abud (2002), o ensino das profissões vinculadas ao Ensino Superior de Ciências Agrárias ocorreu ainda no período Brasil Colônia, quando D. João VI instituiu os primeiros Cursos Práticos de Agricultura, sendo o primeiro criado na Bahia, no ano de 1812 e o segundo criado dois anos depois, no Rio de Janeiro.

Em 1875, a Imperial Escola Agrícola foi criada também na Bahia, com dois tipos de cursos, sendo um elementar, para formação de trabalhadores e regentes agrícolas e florestais, e o superior, objetivando a formação de agrônomos, silvicultores e veterinários. A segunda escola regular de agricultura e veterinária de nível superior do Brasil foi instituída em 1833, na cidade de Pelotas-RS, sendo que nessa escola formouse, em 1915, a primeira mulher diplomada em Agronomia. Em São Paulo, o ensino superior de ciências agrárias, em nível superior, iniciou-se em 1894 e funcionou até 1910, quando o curso foi desativado, e a função de formar profissionais dessa área passou para a Escola Agrícola Prática São João da Montanha, em Piracicaba, que alterou sua denominação para Escola Agrícola Prática "Luiz de Queiroz", e que hoje é a conceituada Escola Superior de Agricultura "Luiz de Queiroz" (FLORENÇANO; ABUD, 2002).

\section{A necessidade e a importância das profissões de Ciências Agrárias}

Com a evolução das atividades comerciais com os produtos oriundos da agropecuária, surgiu o ramo de atividades que se denominou de agronegócio, que é responsável, no Brasil, por grande parcela das exportações. É com a agropecuária e a agroindústria que o país precisa contar para atender as demandas de uma população cada vez maior e mais concentrada nas regiões urbanas. É no meio rural e agrícola que se iniciam as cadeias produtivas da produção de alimentos, que propiciam a produção de bens e serviços, movimentando recursos humanos e materiais, com seus decorrentes impactos econômicos e sociais. No entanto, tudo isso necessita ocorrer em sistemas produtivos que respeitem as condições naturais, as necessidades e os valores humanos, ou seja, sustentáveis em seus aspectos mais amplos, harmonizando a convivência harmônica com os ecossistemas, onde o ser humano é componente inegavelmente importante (ELIAS; ROMBALDI; MENEGUELLO, 2003).

A atuação dos profissionais de Ciências Agrárias sempre esteve e está intimamente relacionada com o desenvolvimento da sociedade, especialmente nos aspectos mais diretamente ligados com a agropecuária e a agroindustrialização. A criação e o aperfeiçoamento das profissões do ramo da Agronomia refletem, de certa forma, uma necessidade e uma disposição de organizar e qualificar o setor produtivo agropastoril, com significação econômica e importância social. O profissional de Ciências Agrárias deve reunir as condições nas áreas técnicas, científicas, sociais/humanísticas e ambientais, de modo a poder executar todas as tarefas que dizem respeito à produção de alimentos para o homem, para os animais domésticos, bem como para as indústrias que utilizam a matéria-prima advinda da agropecuária para atender as mais diversas demandas da sociedade, abrangendo uma área de atuação que vai desde as condições de plantio ou implantação das diversas explorações, até a chegada do produto em condições de serem consumidos pela população. Pode e deve atuar nos setores públicos e privados, nas atividades de planejamento, ensino, pesquisa, extensão e produção (UFSCAR, 2006).

Inúmeras mudanças e transformações estão, na atualidade, transformado o cenário agrícola e agrário brasileiro. Devem ser destacadas as inovações e melhorias tecnológicas e estruturais observadas, como conseqüência de avanços da pesquisa. Simultaneamente ocorreram sérias rupturas nas tradições, nas formas de expressão das diversas culturas e realidades e também nas relações humanas, tanto no ambiente rural quanto no ambiente urbano. Rodovias, ferrovias e infovias provocaram o encurtamento espacial e temporal das distâncias. A sociedade local e a importadora, no exterior, passaram a exercer forte pressão ao exigir produtos agrícolas que sejam, ao mesmo tempo, ambientalmente corretos, seguros para o consumo e de preço acessível. Com isso, surge a crescente responsabilidade do setor agrícola para aumentar a produção a cada ano e, ao mesmo tempo, fixar o morador, produtor e trabalhador rural no campo e imputa-lhe, adicionalmente, a obrigação de preservar o meio ambiente, em especial a água e as matas (UFSCAR, 2006). 
Essa nova realidade e as constantes e crescentes demandas fazem com que a atividade agropecuária e o agronegócio enfrentem inúmeros desafios, que são apresentados tanto para Governos e Sociedade de maneira geral, quanto para o Produtor Rural. Tais desafios podem ser considerados em três enfoques básicos: a questão ambiental, a vertente econômica e a necessidade social. Colocar no rumo e manter o desenvolvimento agrícola em parâmetros que atendam exigências econômicas, sociais e ambientais constitui-se em tarefa muito difícil, que exige mudanças estruturais de médio e longo prazo. O profissional de Ciências Agrárias, vetor efetivo de identificação e pesquisa de novas tecnologias, deve assumir também o papel daquele que deve transformar o conhecimento formal em uma práxis adequada à realidade socioeconômica-cultural, perfeitamente ajustável a cada realidade do meio e do produtor rural. Isso exige que esse profissional possua uma formação integral, do homem para a vida, conciliada com uma formação técnica e especializada, do homem para o trabalho (UFSCAR, 2006).

A temática moderna e as novas demandas, tais como globalização, as questões ecológicas e ambientais e os cuidados referentes à responsabilidade social, impuseram ao profissional de Ciências Agrárias novas dimensões, com perspectivas muito interessantes. Incluem-se aqui também as evoluções das novas biotecnologias e os avanços nas ciências da informação. É importante destacar a internacionalização do agronegócio, que abre novos e importantes postos no mercado de trabalho. A competitividade privilegia os profissionais com formação eclética, que inclua uma compreensão e constante aperfeiçoamento no que diga respeito aos cenários internacionais e as evoluções tecnológicas (CALDAS, 2006).

Portanto, a preparação desse profissional deverá possibilitar-lhe capacidade criativa e crítica, perfeita compreensão do exercício profissional, capacidade de geração, execução e difusão de tecnologia, bem como as condições necessárias para diagnosticar, entender e implantar a transformação do modelo agrícola vigente, para uma agricultura compatível aos interesses sociais da comunidade, permanentemente integrada e em harmonia com o ambiente natural e com o ser humano. Estarão no escopo desse profissional o universo dos conhecimentos que investigam e aperfeiçoam métodos, normas e técnicas, com vistas à exploração econômica da terra, das plantas e dos animais. Sua função primordial consiste em promover a integração do homem com o ambiente natural, por meio da terra, da planta e do animal; consiste também no atuar nos empreendimentos de interesse social e humano e no trato crítico e inovador das questões relacionadas com a melhoria das comunidades rurais e o desenvolvimento agrário (UEMA, 2006).

\section{A subdivisão da Agronomia ou das Ciências Agrárias}

Do ramo das Ciências, denomina Agronomia, ou mais modernamente Ciências Agrárias, surgiu no Brasil a profissão-mater, a Agronomia, a partir das escolas instituídas ainda no período do Brasil Colônia. Com o transcorrer dos anos e das crescentes necessidades de especialização nas inúmeras nuances da produção agropecuária e, mais tarde, da agroindustrialização, várias profissões derivaram dessa "ciênciamãe".

A primeira delas foi a Veterinária, mais tarde denominada Medicina Veterinária, que veio ocupar-se de grande parte das necessidades das explorações e criações de animais. Em seguida, desmembrou-se a Silvicultura, que recebeu posteriormente a denominação de Engenharia Florestal, para ocupar-se, com maior especialização, da questão florestal, tanto no campo ambiental como no campo das explorações econômicas. Em seqüência, desmembrou-se a Zootecnia, com atribuições parciais nas explorações e criações animais, mais efetivamente voltada aos aspectos da produção e tecnologia para tal. A última derivação ocorreu com o desmembramento da Engenharia Rural, depois redenominada de Engenharia Agrícola, com forte especialização nos aspectos das ciências exatas que permeavam a Agronomia. Pode ser citada ainda como profissão derivada a Engenharia de Pesca, embora esta tenha surgido mais modernamente para suprir uma forte lacuna existente nas profissões das Ciências Agrárias, pois a Engenharia Agronômica, a Veterinária e a Zootecnia não conseguiam cobrir todo esse amplo campo de atuação. Nesse ínterim, a profissão de Agronomia passou a receber, com idas e vindas, a denominação de Engenharia Agronômica, para diferenciá-la do ramo das ciências denominado Agronomia. Mais recentemente, a própria Engenharia Florestal deu origem a uma nova profissão: a Engenharia Industrial Madeireira. 
Seja qual for a profissão de Ciências Agrárias, é de sua missão oferecer à sociedade o saber técnico e experiência profissional, em busca de alternativas para o desenvolvimento econômico e a inclusão social, contribuindo para a construção de uma sociedade mais justa e democrática para as presentes e futuras gerações. Isso inclui participar e influir para a construção de um projeto de desenvolvimento econômico nacional, com sustentabilidade ambiental e inclusão social, pois a miséria, o desemprego e a exclusão social são as maiores ameaças ao desenvolvimento social e econômico do nosso país (SENGE-BA, 2006). Isso une, com uma linha mestra comum, as Profissões e as Ciências Agrárias (Agronomia) na construção do futuro.

\section{O exercício profissional}

O exercício profissional das diferentes profissões das Ciências Agrárias é estabelecido por Leis Federais. Com exceção da Medicina Veterinária e da Zootecnia, que têm sua regulamentação estruturada pelo Conselho Federal de Medicina Veterinária e seus respectivos Conselhos Regionais - CRMVs, todas as demais profissões desse campo estão vinculadas ao Conselho Federal de Engenharia, Arquitetura e Agronomia - CONFEA, com seus respectivos Conselhos Regionais - CREAs. Também as profissões de nível médio da Agronomia, tais como os técnicos agropecuários e florestais, estão vinculadas ao Sistema CONFEA/CREAs.

Para o exercício profissional das profissões de Ciências Agrárias, o profissional deve preencher algumas características primordiais, em termos de habilidades pessoais:

- gosto pela natureza e atividade ao ar livre;

- iniciativa;

- desembaraço;

- sociabilidade;

- criatividade;

- raciocínio;

- capacidade de liderança;

- capacidade de trabalho em grupo;

- facilidade de expressão verbal e escrita;

- habilidade matemática;

- interesse pelas ciências naturais;

- interesse por atividades científicas;

- interesse pela pesquisa tecnológica (AEAPB, 2006).

Embora desenhada para as profissões vinculadas ao Sistema CONFEA/CREAs, descreve-se a seguir as principais linhas de atuação, no exercício profissional, dos profissionais de Ciências Agrárias:

- supervisão, coordenação e orientação técnica;

- estudo, planejamento, projeto e especificação;

- estudos de viabilidade técnico-econômica;

- assistência técnica, assessoria e consultoria;

- direção e execução de obra e serviço técnico;

- vistoria, perícia, arbitramento, laudo e parecer técnico;

- desempenho de cargo e função técnica;

- ensino, pesquisa, análise, experimentação, ensaio e divulgação técnica;

- extensão rural;

- elaboração de orçamentos e planos de crédito;

- padronização, mensuração e controle de qualidade;

- fiscalização de obra e serviços técnicos;

- produção técnica e especializada;

- condução de equipe de instalação, montagem, operação, reparo ou manutenção;

- condução de manutenção de equipamento e instalação (CONFEA, 1973). 
Cada uma dessas linhas de atuação se materializa nas especificidades de cada Curso e de cada Profissão, em conteúdos formatados às suas atribuições legais, que qualificam o profissional ao correto e meritório exercício profissional.

\section{CONSIDERAÇÕES FINAIS}

A diversidade de atuação do Profissional de Ciências Agrárias de modo geral e sua importância para o desenvolvimento do país, do meio rural, para a preservação do meio ambiente, para a segurança alimentar e para a manutenção sustentada dos processos produtivos do agronegócio e da agricultura familiar, torna o exercício profissional dessas áreas um fascinante processo de construção, que dignifica e honra quem exerce tais profissões com ética e elevado espírito de cidadania.

Àqueles profissionais que atuam diretamente com o Homem do meio rural e com suas instituições sociais e econômicas, agregam ainda a responsabilidade de auxiliar a transição dessas pessoas de camponeses para cidadãos de pleno direto e reconhecida importância econômica, social e cultural. Essa vertente das profissões de Ciências Agrárias é de tal importância, magnitude e de atuação crítica que deveria ser exigido do todos os profissionais que, além da formação curricular em Sociologia e Extensão Rural, que fizessem um estágio obrigatório nos Serviços Oficiais de Extensão Rural, mormente aqueles que atuam com a Agricultura Familiar e suas organizações.

A questão ambiental, a preservação do meio ambiente, a exigência de sustentabilidade em todos os níveis e o atendimento às crescentes demandas por alimentos primários e transformados apresentam desafios que exigem do profissional qualificação técnica, criatividade, trabalho em equipe, liderança, iniciativa, capacidade de análise e de resolução de problemas, que aliados à formação profissional eclética e multivariada, tornam as profissões da Agronomia um fascinante mundo, talvez sem paralelos em todas as demais profissões, embora sejam todas igualmente meritórias.

Cabe acima de tudo, ao profissional de Ciências Agrárias, como marca de sua conduta, extrapolando a qualificação técnico-científica, assumir elevados deveres de ordem profissional, no que se refere à ética de sua atuação e intervenção, pois desta maneira as ações do Profissional vão se refletir no meio profissional e na comunidade como um todo, estando assim a prática profissional dirigida para atender aos interesses maiores do Homem e da Sociedade.

\section{REFERÊNCIAS}

AEAPB. Definição da profissão: habilidades necessárias. Pato Branco: Associação dos Engenheiros Agrônomos de Pato Branco. 2006. Disponível em: <www.aeapb.com.br>. Acesso em: 07 maio 2006.

CALDAS, R. A. Quatro décadas de Agronomia. Biotec pra galera. 2006. Disponível em: <http:// www.biotecpragalera.org.br/entrevista_ruy_caldas.php>. Acesso em: 12 maio 2006.

CAVALLET, V. J. A formação do engenheiro agrônomo em questão: a expectativa de um profissional que atenda as demandas sociais do século XXI. 1999. 142 f. Tese (Doutorado em Educação)-Faculdade de Educação da Universidade de São Paulo, São Paulo, 1999.

CONFEA. Resolução no 218, de 29 de junho de 1973. Brasília: Conselho Federal de Engenharia, Arquitetura e Agronomia. Disponível em: <http://normativos.confea.org.br/downloads/0218-73.pdf>. Acesso em: 12 maio 2006.

ELIAS, M.; ROMBALDI, C.; MENEGUELLO, G. Mais do que 120 anos de aulas, a trajetória da FAEM representa marcas de uma lição. R. Bras. Agrociência, v. 9, n. 4, p. 313-316, out./dez., 2003.

FLORENÇANO, J. C. S.; ABUD, M. J. M. Histórico das profissões de Engenheiro, Arquiteto e Agrônomo no Brasil. Rev. Ciênc. Exatas, v. 5-8, p. 97-105, 1999-2002. 
SENGE-BA. Manual do engenheiro. Salvador: Sindicato dos Engenheiros do Estado da Bahia, 2006. p. 40.

UEMA. Homenagem ao Dia do Engenheiro Agrônomo. São Luiz: Universidade Estadual do Maranhão, 2006. Disponível em: <http://www.uema.br/noticias/noticia.php?id=3548>. Acesso em: 07 maio 2006.

UFSCAR. A formação do engenheiro agrônomo. São Carlos: Universidade Federal de São Carlos. 2006. Disponível em: <http://www.cca.ufscar.br/formacao.htm>. Acesso em: 12 abr. 2006. 